\title{
Modeling the development of the tourism industry in the smart age of global- ization through transnational cooperation and capacity building
}

\author{
Nadiia Shmygol ${ }^{1, *}$, Olena Cherniavska ${ }^{2}$, Dariusz Pawliszczy ${ }^{3}$, Yeugeniia Shmygol $^{4}$, and Alexandra Cherniavska $^{5}$ \\ ${ }^{1}$ Department of Management, Zaporizhzhia Polytechnic National University, 64 Zhukovskoho Str., Zaporizhzhia, 69600, Ukraine \\ ${ }^{2}$ National Aviation University, 1 Liubomyra Huzara Ave., Kyiv, 03058, Ukraine \\ ${ }^{3}$ Gromadka Commune Office, 9 General Wł. Sikorskiy Str., 59-706 Gromadka, Poland \\ ${ }^{4}$ Warsaw University of Technology, 1 Politechniki Sq., 00-661 Warsaw, Poland \\ ${ }^{5}$ Kyiv National University of Building and Architecture, 31 Povitroflotskyi Ave., Kyiv, 03680, Ukraine
}

\begin{abstract}
The relevance of the chosen topic is related to the growing interest of researchers in technologies and mechanisms of growth of new touristic opportunities in the smart era of society, features of its impact on national policies in order to achieve strategic socio-economic goals of the countries both for domestic territories and along the path of development of geoeconomic strategies in the global space. In addition the relevance of the research direction is enhanced by the fact that tourism is one of the sectors of the world economy that has suffered the most from restrictions on movement during the pandemic crisis. The European Commission has recently presented a series of proposals setting out the foundations of the EU economy and society suitable for the digital age, outlining the development of a genuine European data space and offering a European approach to new technologies. The new industrial strategy and the SME strategy (adopted on March 10, 2020) identify the path to digital transformation to empower industry and small and medium-sized enterprises. The latest strategic communication of the European Commission "Tourism and Transport for 2020 and beyond" emphasizes the role of digital transformation and sustainability. This involves investing in digital skills and promoting digital innovation, as well as linking the tourism business and businesses to existing data spaces, technology providers, and community actors at the local and regional levels. To determine the possibilities of further evelopment of the industry, ithe article proposes a factor model of the total revenue from tourism activities, taking into account regional changes in tourist flow, provide recommendations for the effective development of the industry with account of future trands of tourism industry and ecosystem development. These issues are equally pertinent both for tourism, given the advantages innovative, new technologies can bring to tourism destinations and for businesses, local communities and travellers. They can facilitate tourism management both at destination and business level, contributing to balanced and sustainable growth of tourism in post Pandemic time. New smart technologies can help businesses provide more personalised services and therefore enhance the tourism experience.
\end{abstract}

\section{Introduction}

The European Commission has recently presented a series of proposals [1-8] setting out the foundations of the EU economy and society suitable for the digital age, outlining the development of a genuine European data space and offering a European approach to new technologies.

The new industrial strategy [9] and the SME strategy [10] (adopted on March 10, 2020) identify the path to digital transformation to empower industry and small and medium-sized enterprises. The latest strategic communication of the European Commission "Tourism and Transport for 2020 and beyond" [11] emphasizes the role of digital transformation and sustainability. This involves investing in digital skills and promoting digital innovation, as well as linking the tourism business and businesses to existing data spaces, technology providers, and community actors at the local and regional levels. However, the real

*e-mail: nadezdash@ua.fm volume of domestic tourism is much higher than official statistics show.

The majority of the population, engaged in domestic tourism, prefer individual search for accommodation, food, vehicles, sightseeing facilities, etc. It is not possible to take into account the relevant tourist flows in the calculations.

However, to determine the possibilities of further development of the tourism industry, the article proposes a factor model of the total revenue from tourism activities, taking into account regional changes in tourist flow, provide recommendations for the effective development of the industry with account of future trends of tourism industry and ecosystem development.

Tourism is one of the major components of economic growth for communities worldwide. A key requirement of tourism has been to attract more and more tourists from different parts of the world. Important component of smart city is smart tourism [12]. Smart tourism refers to the ap- 
plication of information and communication technology, such similar to the smart cities, for developing innovative tools and approaches to improve tourism [13, 14].

Tourism ecosystem coversa range of activities such as travel, transport, accommodation, food, recreation on land and water, culture or nature. Directly and indirectly, it contributes close to $10 \%$ to EU GDP and has made the EU the world's leading tourism destination, with 563 million international arrivals and $30 \%$ of global receipts in 2018.

The Treaty on the Functioning of the European Union ("TFEU") outlines the Union's competences in this field (Title XXII Tourism, Article195), specifying that EU measures to support, coordinate or supplement the actions of the Member States shall be especially aimed at: a) encouraging the creation of a favourable environment for the development of undertakings in this sector; b) promoting cooperation between the Member States, particularly by the exchange of good practices [15].

Digital technology is changing people's lives. The EU's digital strategy aims to make this transformation work for people and businesses, while helping to achieve its target of a climate-neutral Europe by 2050. The European Commission is determined to make this Europe's "Digital Decade" [1].

Smart tourism is understood as any public or private actor of the tourism ecosystem facilitating access to tourism and hospitality products and services through making better use of data, innovative digital solutions and new technologies, such as artificial intelligence, blockchain, Internet of Things (IoT), communications systems, cyber security, etc. The overall objective of smart tourism is to offer a more efficient, enhanced and more customised tourism product or service, for the benefit of all actors involved in its development and implementation as well as of travelers and local communities [16].

According with five-year plan on smart tourism released The China National Tourism Administration, all 4A and 5A-rated scenic spots in China are able to provide online booking services, electronic tour guides and free $\mathrm{Wi}-$ Fi to all tourists in 2020, tour buses, cruise ships and scenic spots with large numbers of tourists will have real-time monitoring systems set up to address security concerns, digital technologies will be adopted to improve tourists' experiences, from smart hotels offering check-in via mobile devices to real-time collection of tourist data for tailoring personalized hotel or sightseeing services [17, 18].

A significant contribution to the development of scientific approaches to the development of the tourism industry and the search for effective ways to manage the industry through the development of new marketing methods made in [19-34] and others. However, modern approaches to the management of the tourism industry, with the emergence and development of new organizational forms of management, are constantly changing.

Nowadays, multimedia methods and information tools allow to create more and more ideas about specific travel services. Some travel agencies see a chance to survive in the market by transferring activities to the virtual world. Undoubtedly, this is a way to increase the cluster of potential customers, but it will remain a dubious way to survive for the travel services market, as it concerns only the type of activity and not sales mechanisms [19-21].

However, customers often complain about the lack of flexibility in their offers by virtual travel agencies. More than $70 \%$ of respondents emphasize that there are restrictions imposed on them by sites that sell travel services, and do not recommend using their offers. Thus, thanks to the existence of the Internet, information about travel destinations, for example, can be found more easily, in part, you can choose providers of other services, including globally. Currently, about one third of international tourist trips are organized through the use of online resources, and half of them also involve reservations through the online network [32].

From the point of view of partial service providers, the spread of Internet access opens up many opportunities: new perspectives for action, better access to information, more effective promotion and, finally, direct (cheaper) contact with potential recipients. This allows you to get feedback and respond more quickly to possible changes in the market - that is, the tasks that were previously the responsibility of travel agencies [33].

\section{The main problems of the tourism industry and areas for their solution}

According to official statistics, tourism in Ukraine is about $3-4 \%$ of GDP, which is much lower than the international average of $10 \%$. However, the latest calculations of the UN World Tourism Organization, UNWTO have determined this share at about 9\% of Ukraine's GDP.

Prior to the COVID-19 crisis, tourism in Ukraine was improving after a significant decline due to the events of 2014. Kyiv, Odesa and Lviv were the most developed tourist destinations in terms of the chain of value formation of tourist services, destination management and popularity for the vast majority of international tourists.

According to the State Statistics Service of Ukraine, employment in the field of tourism, excluding the strong transport sector and other components of the tourism economy, is 700-900 thousand jobs, which is the result of the interaction of the accommodation and catering sector with such industries as arts, entertainment and recreation. The structure of subsidiary tourism accounts corresponds to the structure of countries with similar tourism products, but with a much lower share of catering in the overall structure. The transport and culture sector provides a relatively higher level of contributions to Ukraine's economy compared to similar indicators in other countries. Tourism in Ukraine has a high potential for development in products such as weekend tours and business tourism, as well as in the field of natural and cultural resources (tourism, rural tourism, medical facilities/health centers).

With the help of smart technologies, you can really influence the form of the package, the choice of route, service provider, the ability to collect discounts on loyalty programs and, above all, independence in organizing the trip.

The choice of target segments to address the priority problems of the tourism industry of Ukraine in this study is 
proposed to perform using the methodology of factor analysis. The effective indicator will be the total cost of tours sold by tour operators and travel agents (TCTS), which must be maximized due to the identified reserves of its growth based on a comparative analysis of statistics for 2018 and 2019.

Thus, the total cost of vouchers sold according to 2019, in accordance with the areas of tourism, consisted of:

- the cost of vouchers sold to citizens of Ukraine for travel within the country $-1186749,4$ thousand UAH or $6,34 \%$ of the volume of GRP, equal to 18726217,3 thousand UAH;

- the cost of sold vouchers to citizens of Ukraine for travel abroad - 17341997,2 thousand UAH or $92,61 \%$ of the volume of TCTS;

- the cost of sold vouchers to foreigners for travel within Ukraine - 197470,7 thousand UAH or 1,05\% of the volume of TCTS.

As we can see, domestic tourism with the use of tourism entities in Ukraine needs purposeful development. The real volume of domestic tourism is much higher than official statistics show.

The majority of the population, engaged in domestic tourism, prefer to individually search for accommodation, food, vehicles, sightseeing, etc., in order to reduce the cost of recreation. It is not possible to take into account the relevant tourist flows in the calculations. However, we will try to calculate the impact of various factors on increasing sales in the tourism industry.

\section{Construction of a factor model for assessing the prospects for the development of the tourism industry}

The cost of realized vouchers for each direction of tourist activity depends on the corresponding volume of tourist flow, or the number of tourists and the average cost of the realized voucher. Thus, we will have:

$$
T C T S=\sum_{i=1}^{3}\left(V T F_{i} \times A C T_{i}\right),
$$

where TCTS - the total cost of tours sold by tour operators and travel agents in all areas of tourism, $\mathrm{UAH}$;

$V T F_{i}$ - the volume of tourist flow in the $i$-th direction of tourist activity, equal to the number of tourists, people;

$A C T_{i}$ - the average cost of a ticket for the $i$-th direction of tourism.

The index $i=1$ in formula 1 corresponds to the travels of Ukrainian citizens within the country; and $i=2-$ abroad; and $i=3$ - travel of foreigners in Ukraine.

According to the theory of economic analysis, when constructing factor models of multiplicative or additivemultiplicative type, the following rules must be observed:

1. The sequence of factors affects the final result of the analysis. Therefore, in the model it is necessary to place at first quantitative indicators, and then - qualitative. As can be seen, formula 1 corresponds to the specified restriction.
2. If the factor model contains several quantitative or qualitative indicators, then the sequence of their placement depends on the level of subordination to the performance indicator: first there must be factors of a higher level of subordination. As we can see, model 1 consists of two factors of the first level of subordination, so this rule is not relevant for it.

Further decomposition of the factor model 1 into components is due to the qualitative indicator of GRP, which requires consideration of the second rule:

$$
\begin{aligned}
A C T_{i} & =T_{i} \times P T D_{i}= \\
& =\sum_{j=1}^{m}\left(V T F_{S j, i j} \times T_{i j}\right) \times \sum_{j=1}^{m}\left(T D_{S h, i j} \times P T D_{i j}\right)
\end{aligned}
$$

where $T_{i}, P T D_{i}$ - respectively, the average duration of the tour and the average price of one day in tour in the $i$-th direction of tourist activity;

$T_{i j}, P T D_{i j}$, - respectively, the duration of the tour and the price of one tour for the $i$-th direction of tourist activity in the $j$-th region;

$V T F_{S h, i j}$ - the share of the volume of tourist flow of the $j$-th region in the $i$-th direction of tourist activity in VTF;

$T D_{S h, i j}$ - the share of realized tourist days in the $j$-th region in the $i$-th direction of tourist activity;

$m$ - the number of regions for which the assessment is performed.

Substituting formula 2 in 1, we obtain the final form of the factor model of the total cost of vouchers sold in all areas of tourism, taking into account regional changes in tourist flows, duration of vouchers and price levels of one tourist:

$$
\begin{aligned}
& \text { TCTS }=\sum_{i=1}^{3}\left(V T F_{i} \times T_{i} \times P T D_{i}\right)= \\
& =\sum_{i=1}^{m}\left(V T F_{i} \times \sum_{j=1}^{m}\left(V T F_{S j, i j} \times T_{i j}\right) \times\right. \\
& \left.\times \sum_{j=1}^{m}\left(T D_{S h, i j} \times P T D_{i j}\right)\right) .
\end{aligned}
$$

To determine the influence of factors on the performance in model 3 in this study used one of the methods of deterministic factor analysis - the method of chain substitutions. The essence of this method is to consistently replace the basic values of the factors of the level of 2018 with the actual values of 2019 with the subsequent calculation of the changes.

The results of the factor analysis of changes in the total cost of sold vouchers in the areas of tourism are shown in table 1 .

The calculations allow us to analyze the changes in the capacity of the market of tourist services in terms of individual factors and areas of tourism. As you can see from Table 1, during 2018-2019, the total cost of sold vouchers increased by $\triangle T S C T S=472228,9$ thousands of UAH or $2,59 \%$, all areas of tourism had an increase in market capacity. 
Table 1. The results of factor analysis of changes in the total cost of sold vouchers in the areas of tourism during 2018-2019, thousand UAH

\begin{tabular}{|c|c|c|c|c|}
\hline \multirow{3}{*}{$\begin{array}{c}\text { Change in } \\
\text { performance } \\
\Delta T C T S \\
\text { due to } \\
\text { factors }\end{array}$} & \multicolumn{3}{|c|}{ Directions of tourist activity } & \multirow{3}{*}{$\begin{array}{c}\text { Total } \\
\text { changes } \\
\Delta T C T S\end{array}$} \\
\hline & \multicolumn{2}{|c|}{$\begin{array}{c}\text { Travels of citizens } \\
\text { of Ukraine }\end{array}$} & \multirow{2}{*}{$\begin{array}{c}\text { Travels of } \\
\text { foreigners } \\
\text { within } \\
\text { Ukraine }\end{array}$} & \\
\hline & $\begin{array}{c}\text { Within } \\
\text { the } \\
\text { country }\end{array}$ & Abroad & & \\
\hline & 148109,6 & 251407,3 & & 47228,9 \\
\hline$\Delta T C T S_{V T F}$ & 50687,2 & 1214068,0 & & 1282 \\
\hline$\triangle T C T S_{A C T_{i}}$ & 97422,4 & $-962660,7$ & 550 & -81 \\
\hline$\Delta T C T S_{T_{i}}$ & $-155564,1$ & -12780 & $-61141,8$ & $-1494707,0$ \\
\hline$\Delta T C T S_{V T F_{S h, i}}$ & $-116207,2$ & 175084,4 & $-23561,5$ & 35315,7 \\
\hline$\Delta \operatorname{TCTS}_{T_{i j}}$ & $-39356,9$ & $-1453085,6$ & $-37580,2$ & $-1530022,7$ \\
\hline$\Delta T C T S_{P T D_{i}}$ & 252986,5 & 315340,5 & 116205,7 & 684532,7 \\
\hline$\Delta T C T S_{T D_{S h, i j}}$ & 192696,9 & $-58958,7$ & 10549,8 & 144288,0 \\
\hline
\end{tabular}

These changes were due to two factors:

1. The volume of tourist flow, which in 2019 increased by 149,101 people. The corresponding increase in market capacity was equal to $\triangle T C T S_{V T F}=1282403,2$ thousands of UAH. Moreover, only due to the growing number of trips of Ukrainian citizens abroad, this figure increased by $\triangle T C T S_{V T F 2}=1214068,0$ thousands of UAH.

2 . The average cost of sold vouchers, which during 2018-2019 decreased by UAH 319.5. from UAH 8,236.1. up to UAH 7,916.6 per person. These changes had a negative impact on the capacity of the market of tourist services, which decreased by $T C T S_{A C T}=-810174,3$ thousands of UAH. And, on directions of tourist activity the specified situation is ambiguous:

- due to the travels of Ukrainian citizens within the country, the market capacity increased by TCTS $_{A C T_{1}}=97422,4$ thousands of UAH;

- due to the travel of Ukrainian citizens abroad, the cost of vouchers sold tended to decrease significantly by TCTS $_{A C T_{2}}=-962660,7$ thousands of UAH, which is negative;

- due to the travel of foreigners within Ukraine, the target also increased by $T C T S_{A C T_{3}}=-55063,9$ thousands of UAH.

Thus, the generalized factor analysis using model 1 showed an increase in tourist activity of the population of Ukraine with a simultaneous desire to minimize the cost of recreation, primarily by reducing the cost of travel abroad.

The study of the factors that led to the reduction of revenues of the tourism industry in previous periods is an important step in finding reserves for its development in the future. Therefore, the factor of the average cost of sold vouchers is considered in more detail in model 2 . The corresponding analytical calculations are given in table 1 , indicate that:

1. The average cost of sold vouchers, which during 2018-2019 decreased by UAH 319,5 from UAH 8236,1. up to UAH 7916,6 per person. These changes had a negative impact on the capacity of the market of tourist ser- vices, which decreased by $T C T S_{T}=-1494707,0$ thousands of UAH. And, on directions of tourist activity the specified situation is ambiguous:

- due to the travels of Ukrainian citizens within the country, the market capacity increased by $\operatorname{TCTS}_{T_{2}}=-1278001,1$ thousands of UAH;

- due to the travel of foreigners within Ukraine, the target also increased by $T C T S_{P T D_{I}}=252986,5$ thousands of $\mathrm{UAH}$.

2. The average duration of vouchers during the study period decreased in Ukraine from 4,70 to 4,29 days. This led to a reduction in performance by $T C T S_{P T D_{2}}=$ 315340,5 thousands of UAH. All, without exception, areas of tourism have reduced their income due to this factor. The largest losses occurred due to travel of Ukrainian citizens abroad, as $T C T S_{P_{T D}}=116205,7$ thousands of UAH.

3. The average price per day in 2019 tended to increase:

- travel of citizens of Ukraine within the country - from UAH 586,8 up to $745,8 \mathrm{UAH}$. As a result, the total cost of sold vouchers increased by $T C T S_{P T D}=684532,7$ thousands of UAH;

- travel of citizens of Ukraine abroad - from 2016,8 UAH up to 2054,1 UAH;

- travel of foreigners within Ukraine - from UAH 720,6 up to $1751,1 \mathrm{UAH}$. This led to an increase in revenues by $T C T S_{V T F n T}=35315,7$ thousands of UAH.

Accordingly, the average price of one tour in Ukraine as a whole increased from UAH 1752,3 up to UAH 1845,6.

Thus, the increase in ticket prices in 2019 did not lead to a reduction in tourist traffic. However, the limited holiday budget has led to a reduction in the average duration of vouchers.

Regional structural changes in the volume of tourist flow allowed the tourism industry of Ukraine to receive additional income in the amount of thousands of UAH. by redistributing the number of tourists from those areas where the reduction in the average duration of trips was the most significant, in favor of other areas where a similar reduction was less noticeable.

\section{Consequences of the pandemic and measures to mitigate them}

Tourism is one of the sectors of the world economy that has suffered the most due to restrictions on movement (figure 1). Governments responded immediately to the need to minimize the economic impact of the COVID-19 pandemic, based on two common approaches to managing the situation: the first is to provide affordable credit lines for business, and the second is to defer payment of debts and taxes.

The issue of opening borders for the tourism sector is still unclear. A number of tourism-oriented countries are urging governments to open borders and provide technical solutions that will allow for regular tourist visits. Because decision-making balances economic factors with potential 


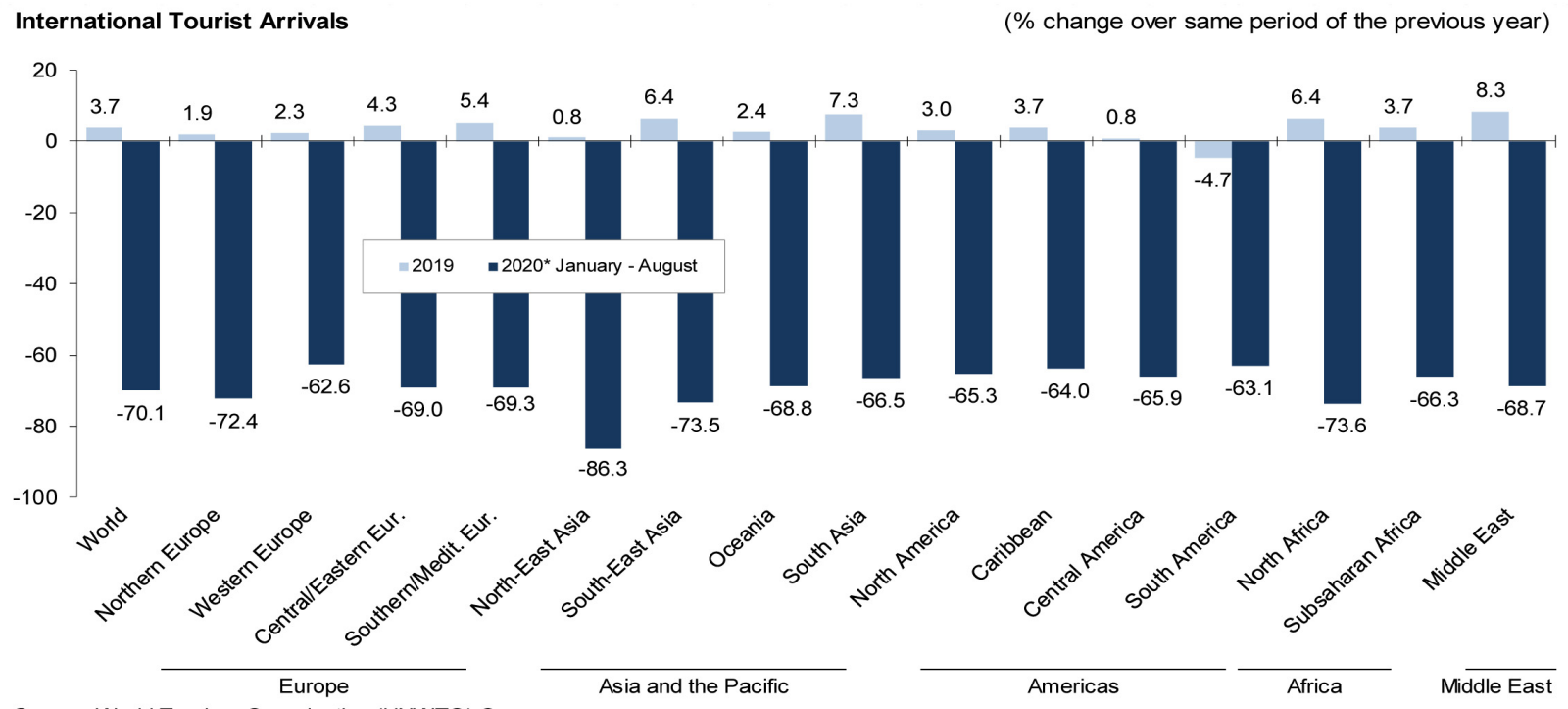

Figure 1. International tourist arrivals [35]

risks to human health, the measures taken by governments can be divided into three main categories: ensuring a fair balance between the protection of tourists and the interests of tourism workers; providing conditions for business survival throughout the supply chain with a special focus on SMEs; focusing on coordination mechanisms to better address and support the recovery of the tourism sector.

Countries that have already overcome the peak of COVID-19 are gradually lifting restrictions on business and services, but with regard to tourism, it is recovering locally. Under favorable conditions, it is assumed that the next step in the recovery of the tourism industry will be the opening of borders between neighboring countries, where the situation is relatively similar (for example, Australia and New Zealand, Thailand and China, etc.).

The European Commission has issued a number of recommendations for the opening of borders in two stages, and the second stage is planned to lift all coronavirusrelated restrictions between member states. Regarding the opening of the EU's external borders to third-country nationals (including Ukraine), the situation remains uncertain.

In general, the losses of the tourism industry in Ukraine are estimated at more than 1.5 billion dollars USA [36]. Along with outbound tourism, domestic tourism also suffered significant losses. The introduction of restrictive measures has negatively affected the leisure and travel industry, as well as related industries - hotel and restaurant business, transport (passenger traffic), retail, entertainment and cultural institutions.

The Government of Ukraine continues to work to minimize the effects of the pandemic on the national economy and has proposed a number of measures, both financial and non-financial, aimed at mitigating the impact of these effects on public life, business and the economy. It was be allocated UAH 4 billion to compensate for interest on existing loans for micro and small enterprises, as well as an expanded program of available loans (5-7-9\%); UAH 24 billion to provide loans with state investment guarantees; UAH 1.6 billion in support of creative industries.

The deadline for payment of taxes on land, land rent and real estate tax, which was due in April 2020, was extended to June 30, 2020, and similar taxes for March 2020 were abolished. Temporary unemployment benefits were provided for those who lost their jobs as a result of the COVID-19 pandemic, in the amount of two thirds of the amount of wages for each reduced working hour, but not more than the established minimum monthly wage (currently $\mathrm{UAH} 4,723$ or $€ 150$ ).

The government reorganized the Department of Tourism and Resorts of the Ministry of Economy and Trade of Ukraine and established the State Agency for Tourism Development. Currently, efforts are aimed at strengthening the position of the State Agency through human resources and financial support from the state budget.

A draft law was submitted to the Verkhovna Rada of Ukraine, which provided for the exemption of tourism service providers from VAT, payment of income tax and the Single Social Contribution, payment of land tax and tax on nonresidential real estate; cancellation of payment of tourist tax; exemption from taxation when paying rent and land use, tenants of state and public property.

On May 27, 2020, the Government of Ukraine approved a program to stimulate the economy to overcome the effects of the COVID-19 epidemic. The program includes initiatives in the following areas: access to finance, access to markets, deregulation, modernization and development, access to infrastructure.

However Ukraine is still significantly behind in implementing measures to support the tourism sector which seriously jeopardizes the industry's competitiveness in the global market during the projected recovery in 2021 [36]. 


\section{Conclusions}

Thus, based on data from factor analysis and trends in Ukraine's tourism industry, traditionally the most effective reserves for growth in tourism revenues was to increase the average duration of trips, expanding the geography of tourist destinations, including foreign ones. According to the scenarios for this sector, the number of international tourists could decrease by $58-78 \%$, leading to a decrease in tourism revenues from $\$ 1.5$ trillion. In such conditions, domestic tourism, including informal tourism, is acquiring new significance. Vodafone Ukraine noted a significant increase in the number of subscribers on Ukrainian southern resorts in summer 2020 compared to summer 2019: Odessa, Mykolaiv and Kherson regions (by 30\%); Kirilivka resorts (by 55\%); Berdyansk resorts (by 37\%); Azov resorts of the under-control part of Doneck region resorts (by 100-170\%). The calculation of real income from domestic tourism is difficult due to the existing practice of statistical accounting, as well as the fact that not all touristic places pay a tourist tax, the bulk of domestic travel is organized independently without contacting travel agencies.

Smart technologies make people more flexibile in touristic activities. New meaning and distribution acquire also such alternative directions as smart tourism, staycation (day trip distance without overnight accommodation) and workation (working vacation) that blends leisure and productive time.

Workations is emerging as a popular engagement strategy as collaboration tools and advancements in workplace productivity technologies (laptops, project management software, and teleconferencing) have made it easier combine work and tourism to stay in the loop on work while enjoying time off in remote locales. Organisation and strategic communication of the European Commission "Tourism and Transport for 2020 and beyond" involves future investing in digital skills and promoting digital innovation, as well as linking the tourism business and businesses to existing data spaces, technology providers, and community actors at the local and regional levels. So modeling the development of the tourism industry became in the smart age of globalization through transnational cooperation and capacity building in the touristic and non touristic industries.

Digital technologies and smart tourism techniques can help reduce the environmental impact of the travel and tourism value chain and green the industry. Because of the horizontal nature of tourism activities, effective support can actually generate sustainable jobs and growth for the entire ecosystem, with positive impacts on countries and local communities

The latest strategic communication from the European Commission, Tourism and Transport 2020 and Beyond, highlights the role of digital transformation and sustainability. Both were cited as key elements of immediate recovery and long-term balanced development and growth in tourism.

This includes investing in digital skills and stimulating digital innovation, as well as connecting tourism busi- nesses and participants to existing data spaces, technology providers, and government actors at the local and regional level. As the Communiqué highlights, in this transition period, small and medium-sized enterprises will need special attention and assistance in understanding the benefits of digital transformation and innovation in order to become more resilient and competitive.

\section{References}

[1] European Commission, A Europe fit for the digital age: Empowering people with a new generation of technologies (2021), https://ec.europa. eu/info/strategy/priorities-2019-2024/ europe-fit-digital-age_en

[2] European Commission, Data governance and data policies at the European Commission, https: //ec.europa.eu/info/sites/default/files/ summary-data-governance-data-policies_ en.pdf

[3] European Commission, Communication: Shaping Europe's digital future (Publications Office of the European Union, Luxembourg, 2020), https:// tinyurl.com/3xjaj5tt

[4] European Commission, On Artificial Intelligence - A European approach to excellence and trust (2020), https://tinyurl.com/4tpka957

[5] European Commission, COMMUNICATION FROM THE COMMISSION TO THE EUROPEAN PARLIAMENT, THE COUNCIL, THE EUROPEAN ECONOMIC AND SOCIAL COMMITTEE AND THE COMMITTEE OF THE REGIONS: A European strategy for data (2020), https: //eur-lex. europa.eu/legal-content/EN/TXT/?qid= $1582551099377 \&$ uri=CELEX : 52020DC0066

[6] European Commission, REPORT FROM THE COMMISSION TO THE EUROPEAN PARLIAMENT, THE COUNCIL AND THE EUROPEAN ECONOMIC AND SOCIAL COMMITTEE: Report on the safety and liability implications of Artificial Intelligence, the Internet of Things and robotics (2020), https://eur-lex. europa.eu/legal-content/en/TXT/?qid= 1593079180383\&uri=CELEX\%3A52020DC0064

[7] European Commission, Factsheets: a europe fit for the digital age (2020), https: //ec.europa.eu/info/publications/ factsheets-europe-fit-digital-age_en

[8] European Commission, COMMUNICATION TO THE COMMISSION: Data, information and knowledge management at the European Commission (2016), https: //ec. europa.eu/info/sites/default/files/ communication-data-knoweldge-management_ en.pdf

[9] European Commission, European industrial strategy (2020), https://ec.europa.eu/ info/strategy/priorities-2019-2024/ 
europe-fit-digital-age/

european-industrial-strategy_en

[10] European Commission, COMMUNICATION FROM THE COMMISSION TO THE EUROPEAN PARLIAMENT, THE COUNCIL, THE EUROPEAN ECONOMIC AND SOCIAL COMMITTEE AND THE COMMITTEE OF THE REGIONS: An SME Strategy for a sustainable and digital Europe (2020), https: //ec.europa.eu/info/sites/info/files/ communication-sme-strategy-march-2020_ en.pdf

[11] European Commission, COMMUNICATION FROM THE COMMISSION TO THE EUROPEAN PARLIAMENT, THE COUNCIL, THE EUROPEAN ECONOMIC AND SOCIAL COMMITTEE AND THE COMMITTEE OF THE REGIONS: Tourism and transport in 2020 and beyond (2020), https : //eur-lex.europa.eu/legal-content/EN/ TXT/PDF/?uri=CELEX : 52020DCQ550\&from=EN

[12] Z. Lijing, P. Yanrong, H. Jianhua, The Development Strategy for the Tourism in Hebei under the Background of Smart City Based on Data Mining, in 2014 7th International Conference on Intelligent Computation Technology and Automation (2014), pp. 991994

[13] A.K. Tripathy, P.K. Tripathy, N.K. Ray, S.P. Mohanty, IEEE Consumer Electronics Magazine 7, 32 (2018)

[14] R. Smith, SMART Tourism Tools: Linking Technology with the Touristic Resources of City Destinations (2015), https://documents.nhtv.nl/load. aspx?doc $=$ thesis $\% 5$ C2015\%5CAT\%5CITMC\% 5CSmithR.pdf

[15] World Tourism Organization, European Union Tourism Trends (UNWTO, 2018), ISBN 978-92844-1946-3, https://www.e-unwto.org/doi/ $\mathrm{pdf} / 10.18111 / 9789284419470$

[16] Europian Commission, Boosting the uptake of digitalisation, innovation and new technologies in tourism through transnational cooperation and capacity building (2020), https://ec.europa.eu/ easme/en/

[17] S. Zhou, Smart tourism plan to focus on digital technologies, https://www.chinadaily.com.cn/ china/2017-03/08/content_28472460.htm

[18] O. Cherniavska, Y.R. Liu, O. Cherniavska, I. Khan, O. Zham, International Journal of Management 11, 185 (2020)
[19] K. Zaychuk, Directions of state regulation of tourist markets, in Intern. Research Practice Conf. (2017), pp. 13-15

[20] O. Strishenetz, Theoretical aspects of formation and development of the cross-border market of tourist and recreational services. Structural Changes in the Economics of Environmental Management: Theoretical Foundations and Applied Aspects (2016)

[21] V. Sarichev, Statistics of Ukraine 2014, 80 (2014)

[22] I. Matyushenko, S. Berenda, V. Reznikov, Ukraine's European Integration in the System of International Economic Integration (V.N. Karazin KhNU, Kharkiv, 2015)

[23] On tourism: The law of ukraine of 15.09.1995. № 324/95, https://zakon.rada.gov.ua/laws/ show/324/95-\%D0\%B2\%D1\%80\#Text

[24] N. Alpatova, All about accounting 31, 7 (2008)

[25] S. Shevchenko, Scientific Bulletin of NLTU of Ukraine 23, 124 (2013)

[26] O. Fedak, Debit-Credit 13, 51 (2008)

[27] V. Vitlinsky, A. Skrypnyk, Finances of Ukraine 12, 19 (2005)

[28] O. Davidova, An efficient economy 10, 21 (2012)

[29] V. Goncharov, M. Zos-Kior, B. Rakhmetulina Zhibek, Current economic issues 10, 118 (2013)

[30] M. Zos-Kior, I. Kuksa, V. Ilyin, A. Chaikina, Economic Annals-XXI 161, 43 (2016)

[31] Y. Bilan, M. Zos-Kior, V. Nitsenko, U. Sinelnikau, V. Ilin, Journal of Security and Sustainability 7, 287 (2017)

[32] V. Gryshko, M. Zos-Kior, O. Zerniuk, International Journal of Engineering \& Technology 7, 131 (2018)

[33] M. Zos-Kior, I. Kuksa, I. Samoilyk, M. Storoška, Economic Annals-XXI 168, 4 (2018)

[34] I. Kuksa, L. Vasyurenko, A. Litvinov, O. Lytvynova, I. Shtuler, M. Zos-Kior, O. Naholiuk, Accounting 6, 913 (2020)

[35] L. Pasternak, UNWTO: International tourism plunges $70 \%$ as travel restrictions impact all regions (2020), https://tinyurl.com/vmwdp9ux

[36] Hotel \& Destination Consulting, The COVID-19 pandemic and its consequences in the field of tourism in Ukraine. Update to the document "Road map of competitive development of tourism in Ukraine (2020), http://www.ntoukraine.org/assets/ files/EBRD-COVID19-Report-UKR.pdf 